\title{
A FORMAÇÃO E A ATUAÇÃO DOCENTE NA EDUCAÇÃO PROFISSIONAL E TECNOLÓGICA: O QUE REVELAM AS PESQUISAS DOS ÚLTIMOS DEZ ANOS?
}

\author{
Fabíula Tatiane Pires \\ Instituto Federal de Minas Gerais \\ DOI: 10.15628/rbept.2019.8573 \\ Artigo submetido em abr/2019 e aceito em jul/2019
}

\begin{abstract}
RESUMO
Em 2018, os Institutos Federais de Educação, Ciência e Tecnologia (IFs) completaram dez anos de sua criação. Eles tiveram sua origem a partir da reestruturação dos Centros Federais de Educação Tecnológica (CEFETs), das escolas técnicas e agrotécnicas federais e das escolas vinculadas às Universidades Federais. Seu marco legal data da promulgação da lei n. 11.892/08. Nesse período, um número significativo de professores ingressou nos IFs, dada a expansão e a interiorização destes. Assim, este trabalho tem como objetivos identificar, analisar e sintetizar a produção científica da área, no que se refere à formação e à atuação dos docentes da Educação Profissional e Tecnológica (EPT). Para tanto, realizou-se um levantamento bibliográfico, em dezembro de 2018, nas seguintes fontes de referência: Revista Brasileira de Educação, Revista Educação e Sociedade, Revista Brasileira da Educação Profissional e GT 8 - Formação de Professores da ANPEd, no período de 2008 a 2018. Os resultados encontrados revelam a predominância de algumas temáticas, a saber: legislação referente à formação de professores da EPT; saberes docentes; formação continuada; conteúdo de formação; atuação marcada pela inserção no mercado de trabalho; identidade em construção.
\end{abstract}

Palavras-Chave: Institutos Federais; Formação docente; Atuação Docente; Revisão de literatura.

\section{THE QUALIFICATION AND ACTION OF PROFESSIONAL AND TECHNOLOGICAL EDUCATION TEACHERS: WHAT DO THE LAST TEN YEARS OF RESEARCH REVEAL?}

\begin{abstract}
In 2018, the Federal Institutes of Education, Science and Technology (IFEST) has completed ten years since their creation. The Institutes have been created by the restructuring of the Federal Centers of Technologic Education (FCTE), of the federal technical an agrotechnical schools and of the schools that were linked to Federal Universities, and its legal framework is dated by the promulgation of the law 11.892/08. In that period a significative number of teachers ingressed in the institutes, due to the expansion and interiorization of them. In this context, this paper has as objective the identification, analysis and syntheses of the scientific production of the Education area regarding the qualification and action of the Professional and Technologic Education (PTE) teachers. For that matter a bibliographic research was made in December of 2018, using the following references: Revista Brasileira de Educação, Revista Educação e Sociedade, Revista Brasileira da Educação Profissional e GT 8 - Formação de Professores da ANPEd, in the 2008-2018 interval. The results reveal the predominance of some themes, namely: legislation about the qualification of EPT's teachers; teaching knowledge; continuing education; content to qualification; action marked by the inception in the job market; constructing identity.
\end{abstract}

Keywords: Federal Institutes; Teachers' qualification; Teachers' action; Literature revision. 


\section{INTRODUÇÃO}

A Educação Profissional e Tecnológica (EPT), no Brasil, é ofertada, em sua maioria, na rede privada; no entanto, tem nos Institutos Federais de Educação Ciência e Tecnologia (IFs) um importante potencial de oferta. Os IFs tiveram sua origem a partir da reestruturação dos Centros Federais de Educação Tecnológica (CEFETs), das escolas técnicas e agrotécnicas federais e das escolas vinculadas às Universidades Federais (SILVA, 2009). Seu marco legal data da promulgação da lei n. 11.892/08 (BRASIL, 2008). Atualmente, há 38 IFs no Brasil, presentes em todos os estados e, junto ao CEFET-MG, CEFET-RJ, Colégio Pedro II e escolas vinculadas às Universidades, compõem a Rede Federal de Educação Ciência e Tecnologia (REFECT).

Com uma proposta arrojada, os IFs ofertam a educação em todos os níveis e modalidades: formação inicial e continuada; ensino médio integrado; ensino técnico concomitante ao ensino médio; ensino técnico subsequente ao ensino médio; ensino superior (bacharelado, licenciatura e tecnólogo); pósgraduação lato e stricto sensu. Somam-se à oferta do ensino, a pesquisa e a extensão em articulação com os arranjos produtivos locais ${ }^{1}$.

O professor, ao lado de profissionais de outras áreas, tais como pedagogos, psicólogos, assistentes sociais, entre outros, é o profissional com a responsabilidade de fazer girar as engrenagens do ensino, da pesquisa, da extensão e, por vezes, da gestão desses IFs. Assim, pode-se afirmar que a atuação docente nos IFs se caracteriza pela polivalência, não só pelo ensino (diferentes níveis e modalidades), presencial e a distância, mas, também, pela pesquisa e pela extensão que devem articular-se ao mundo do trabalho e aos arranjos produtivos locais. Além disso, parte considerável dos docentes atua na gestão administrativa da Instituição.

O que se conhece sobre a formação e a atuação dos docentes da EPT? Em busca de respostas a esta pergunta, realizou-se um levantamento bibliográfico a fim de conhecer as sistematizações no campo da formação docente dos profissionais que atuam na EPT. Embora o maior número de matrículas na EPT esteja concentrado na rede privada, a maior parte dos estudos sobre a formação de professores da EPT se refere à Rede Federal, tal como destacado por Paiva, Correia e Batista (2017). Nesse sentido, os IFs possuem lócus privilegiado. Os resultados aqui expressos revelam, em sua maioria, a realidade nos IFs.

\section{SOBRE A FORMAÇÃO DOCENTE PARA ATUAR NA EPT: O QUE DIZ A LEGISLAÇÃO}

A formação docente para a EPT, embora esteja presente nas pautas de discussões há alguns anos, continua como um desafio a ser enfrentado,

\footnotetext{
${ }^{1}$ Arranjos produtivos locais entendidos como uma concentração de atividades e/ou empresas dos setores primário, secundário ou terciário em uma dada localidade/região. 
não só nas políticas educacionais, como também na efetivação de sua oferta. Em primeiro lugar, temos na EPT um grupo docente bastante heterogêneo quanto à sua formação inicial: professores técnicos com habilitação de ensino médio; professores bacharéis, sem formação pedagógica; e professores licenciados, com pouco ou nenhum conhecimento sobre Educação Profissional (EP) e mundo do trabalho. A diversidade desse público impõe propostas de formação diferenciadas. Machado (2008) apresenta algumas dessas propostas: i) cursos de licenciatura para graduados - bacharéis sem formação pedagógica; ii) curso de licenciatura integrado com o curso de graduação em tecnologia - para os que estão no processo de formação inicial; iii) curso de licenciatura para técnicos de nível médio ou equivalente, para os docentes que ainda não possuem formação em nível superior; e iv) cursos de licenciatura para concluintes do ensino médio, para aqueles que terminaram este segmento de ensino e pretendem ingressar na carreira docente na EPT.

Para além da organização dos cursos, outro desafio passa pelo conteúdo dessa formação, pois, ainda segundo Machado, é preciso uma "atenção cuidadosa aos conteúdos pedagógicos e educacionais" (MACHADO, 2008, p. 20), e "é fundamental trabalhar diferentes formas de transposição didática dos conteúdos específicos" (MACHADO, 2008, p. 21).

Dito sobre as dificuldades práticas de concepção da formação docente para a EPT, é preciso reconhecer, tal como Oliveira (2005), o caráter emergencial e especial que a legislação educacional para a área tem apresentado. No que se refere à formação docente para atuar no ensino técnico, a Resolução n. 2 (BRASIL, 1997) dispõe sobre os programas especiais de formação pedagógica que são propostos com caráter equivalente à diplomação em licenciatura, a despeito da sua carga horária reduzida em comparação com a dos cursos de licenciatura.

Mais recentemente, a Medida Provisória (MP) n. 746, de 22 de setembro de 2016 (BRASIL, 2016), prevê ainda como um percurso formativo o reconhecimento de profissionais com notório saber sobre as áreas técnicas, habilitando-os para ministrar aulas nos cursos técnicos e profissionais, sem a necessidade de formação pedagógica para tal.

Para Oliveira (2005), a política de formação docente para o ensino técnico, no Brasil, revela-se por um caráter "especial" e "emergencial", além de faltar-lhe integralidade própria. Consolidou-se, pelos programas especiais, o acréscimo da formação pedagógica à formação profissional técnica ou superior, na área em que o profissional leciona. Também falta à área uma política de Estado que se comprometa, não com as oscilações do mercado, mas com uma educação que possibilite "o fortalecimento das relações entre cultura e trabalho, entre ciência, técnica e tecnologia, e a integração entre formação geral e formação específica" em favor dos sujeitos da EP (OLIVEIRA, 2005, p. 16).

Há ainda docentes licenciados atuando na EP; esses, por sua vez, embora tenham passado pela formação pedagógica, desconhecem, em sua maioria, as especificidades da EP, com dificuldade para relacionar, de forma crítica, a educação ao mundo do trabalho. A EPT relegada aos 
"desfavorecidos da fortuna" permanece ainda hoje, particularmente no que se refere à formação de seus professores, ocupando um lugar social de menor prestígio e visibilidade.

\section{PERFIL GERAL DE FORMAÇÃO DOS PROFESSORES DA EPT}

Em pesquisa recente, Pena (2018a), realizando um levantamento sobre o perfil dos docentes no Instituto Federal Minas Gerais (IFMG), constatou que $89 \%$ dos docentes ingressantes (2009-2017) eram mestres ou doutores. Em estudo anterior, Pena (2014) havia identificado, particularmente em um campus desse IF, que entre os docentes de disciplinas técnicas que atuavam na Educação Profissional Técnica de Nível Médio (EPTNM), 70\% eram mestres ou doutores; já nas disciplinas das áreas básicas, esse índice subia para $71 \%$ (PENA, 2014, p. 30). O que se conclui, portanto, é que, apesar do pouco investimento em formação pedagógica, de maneira geral, os professores possuem qualificação e titulação em suas áreas de atuação.

Em pesquisa realizada com professores de disciplinas técnicas, com formação pedagógica, que lecionam na EPTNM, Pires (2015) identificou um perfil de formação próximo ao apresentado por Pena $(2014 ; 2018 a)$. O grupo de professores, sujeitos da pesquisa, possui um bom nível de qualificação, uma vez que todos possuem como titulação mínima o mestrado, e soma-se a essa formação aquela específica para atuação como docente, o que demonstra que, além dos investimentos em conhecimentos de natureza técnica, houve também o seu interesse pelos conhecimentos pedagógicos.

Vale destacar, conforme Pires (2015), que, apesar dos limites da licenciatura, identificados pelos professores de disciplinas técnicas que a cursaram, sua realização permitiu a eles:

vivenciarem um momento de reflexão e de trocas com os professores e com os outros alunos em processo de formação; conhecerem diferentes formas de propor o ensino, atentando para as possibilidades de aprendizagem dos alunos; compreenderem os aspectos políticos da educação, o que favorece a adoção de uma postura crítica frente aos problemas e desafios enfrentados; e, por fim, essa formação lhes permite uma ação docente mais refletida e menos baseada no senso comum. (PIRES, 2015, p. 86)

Torna-se relevante dizer que o perfil formativo de docentes que atuam na RFEPCT difere-se do daqueles que atuam na EPT da rede privada. Em estudo realizado por Paiva, Correia e Batista (2017) com professores da

\footnotetext{
${ }^{2}$ Termo utilizado no decreto n. 7566, de 1909, quando da criação das Escolas de Aprendizes Artífices. BRASIL. Decreto no 7.566, de 23 de setembro de 1909. Crêa nas capitaes dos Estados da Republica Escolas de Aprendizes Artifices, para o ensino profissional primario e gratuito. Disponível em: http://legis.senado.gov.br/norma/589450. Acesso em: 21 jun. 2019.
} 
EPT da rede privada do Rio Grande do Norte, e que lecionam disciplinas da área geral ${ }^{3}$, apontou-se a prevalência de professores "licenciados habilitados às disciplinas na Educação Básica sendo também identificado outro perfil que são os profissionais graduados na área especifica em que atuam, mas não licenciados" (PAIVA; CORREIA; BATISTA, 2017, p. 164). Soma-se a isso, conforme aponta o estudo, o fato de apenas um professor, sujeito da pesquisa, possuir a titulação de mestre.

Em síntese, pode-se afirmar que os IFs, em relação à rede privada que oferta EPT, possuem um quadro docente com maior qualificação, o que pode estar relacionado à sua particularidade de oferta de ensino nos diferentes níveis e modalidades, bem como ao seu compromisso com a pesquisa e extensão e ao plano de carreira, que prevê, entre outros aspectos, o regime de dedicação exclusiva (DE), e a remuneração decorrente da titulação.

\section{O QUE REVELAM AS PESQUISAS SOBRE A FORMAÇÃo E A ATUAÇÃO DOCENTE NA EPT}

Com o intuito de conhecer os resultados de pesquisas realizadas nos dez anos de criação dos IFs, no que se refere à formação e à atuação dos docentes da EPT, foi realizado um levantamento bibliográfico nas seguintes bases de dados: reuniões nacionais da Associação Nacional de PósGraduação e Pesquisa em Educação (ANPEd) - Grupo Temático GT-8: Formação de Professores, por concentrar quantitativa e qualitativamente pesquisas sobre a Formação Docente; Revista Brasileira de Educação e Revista Educação e Sociedade - periódicos Qualis A1; Revista Brasileira da Educação Profissional e Tecnológica, por aglutinar pesquisas que tratam especificamente da EPT; e Biblioteca Digital Brasileira de Teses e Dissertação (BDTD), por concentrar as dissertações e teses defendidas no país. Delimitaram-se, como período para a pesquisa bibliográfica, os dez anos de criação dos IFs (2008-2018).

Foram lidos os títulos dos trabalhos, procurando identificar aqueles que abordavam a formação e a atuação de professores/docentes na EPT, particularmente, nos periódicos. Foram considerados os trabalhos publicados na seção "Artigos". Por fim, na BDTD, utilizaram-se como entradas no campo de busca: I - formação docente para a Educação Profissional e Tecnológica; e II - atuação docente na Educação Profissional e Tecnológica.

A Tabela 1 expressa quantitativamente os resultados encontrados.

\footnotetext{
${ }^{3}$ Paiva, Correia e Batista (2017) denominam "área geral" as disciplinas comuns encontradas em toda a Educação Básica: Língua Portuguesa, Matemática, Geografia, História e Biologia, distinguindo-as, portanto, das disciplinas técnicas, que estão ligadas a um curso técnico. 
Tabela 1 - Quantidade de trabalhos publicados por base pesquisada

\begin{tabular}{|c|c|c|c|}
\hline Fonte de Referência & $\begin{array}{l}\text { Total de trabalhos } \\
\text { publicados }\end{array}$ & $\begin{array}{l}\text { Total de trabalhos } \\
\text { sobre a atuação e a } \\
\text { formação docente } \\
\text { na EPT por fonte }\end{array}$ & $\begin{array}{l}\text { Ano em que os } \\
\text { trabalhos foram } \\
\text { publicados }\end{array}$ \\
\hline ANPEd & 178 & 2 & $2008 ; 2015$ \\
\hline Revista Brasileira de Educação & 474 & 1 & 2014 \\
\hline Revista Educação \& Sociedade & 369 & 2 & 2011 \\
\hline Revista Brasileira da Educação Profissional e Tecnológica & 127 & 23 & $\begin{array}{c}2008 ; 2012 ; 2014 ; \\
2015 ; 2016,2017 ; \\
2018 \\
\end{array}$ \\
\hline BDTD & - & 4 & $2012 ; 2014 ; 2016$ \\
\hline \multicolumn{2}{|c|}{ Total de trabalhos sobre a atuação e a formação docente na EPT } & \multicolumn{2}{|c|}{32} \\
\hline
\end{tabular}

Fonte: Elaborado pelo autor com dados da pesquisa bibliográfica (2018)

Pela análise quantitativa da Tabela 1 , é possível concluir que a temática da formação e da atuação docente na EPT encontra-se ainda pouco pesquisada, dado o número reduzido de publicações. Entre os 32 trabalhos, predominam aqueles que tratam da formação docente na EPT, seguidos daqueles que versam sobre a atuação na EPT.

Após a leitura dos artigos e dos resumos das teses e dissertações, os trabalhos foram agrupados por temáticas proximais. Os resultados serão apresentados a seguir, na seguinte ordem: formação docente para/na EPT e atuação docente na EPT; no entanto, essa é uma organização apenas didática de escrita. Na prática, tornam-se indissociáveis formação e condição de atuação.

\section{FORMAÇÃO E SABERES DOCENTES NA EPT}

Considerando os estudos sobre a formação dos docentes que atuam na EPT, algumas temáticas têm sido abordadas com mais interesse pelos pesquisadores. Entre elas, estão os estudos sobre os saberes docentes, presentes nos trabalhos de Rosa (2012); Souza, Andrade e Aguiar (2014); Silva Júnior e Gariglio (2014); Rodrigues e Freitas (2016); Fonseca (2017); Costa, A., Fonseca e Costa, L. (2017). Inquieta os pesquisadores a forma como professores sem formação para a docência constroem os saberes próprios dessa profissão. Nesse sentido, os resultados das pesquisas indicam que esses saberes são construídos e fundamentados nas experiências pessoais e acadêmicas (RODRIGUES; FREITAS, 2016). Trata-se de saberes da experiência de vida, saberes escolares - do tempo em que se era aluno, e, também, saberes adquiridos na prática docente (FONSECA, 2017). O saber adquire uma característica forte de individualidade do sujeito que sabe; nesse sentido, Rosa (2012) conclui em sua tese que, por meio da mobilização de seus saberes, os professores podem desenvolver atitudes éticoformativas.

Se o tempo e o espaço de aquisição de saberes são distintos para cada professor, a relação desses com os saberes também. Segundo Silva 
Júnior e Gariglio (2014), os saberes são hierarquizados pelos professores de disciplinas técnicas/tecnológicas. Em ordem decrescente estão: o saber do conteúdo, o saber da experiência e o saber pedagógico. Entre as fontes de aquisição, estão a vivência no chão de fábrica ou no mercado de trabalho, a experiência de professores com mais tempo de trabalho, e, por fim, os conhecimentos e habilidades pedagógicas adquiridos na experiência docente.

Considerando-se que a formação docente se dá em momentos distintos da trajetória histórica das experiências sociais e profissionais, tal como nos afirma Costa, A., Fonseca e Costa, L. (2017), tal formação não se encerraria, por exemplo, na conclusão de uma licenciatura, mas se estenderia ao longo da vida. Para Souza, Andrade e Aguiar (2014), o saber pedagógico é aprendido para além da formação recebida; no entanto, necessário considerar que as contribuições advindas da formação favorecem a reflexão sobre esse saber.

\section{POLÍTICAS EDUCACIONAIS PARA A FORMAÇÃO DOCENTE NA EPT}

Presença forte, nos estudos sobre a formação docente na EPT, é daqueles que abordam aspectos da legislação ou das políticas educacionais para Área. Entre os levantados estão: Machado (2008, 2011); Araújo (2014); Vieira et al. (2014); Souza et al. (2014); Silveira, Gonçalves e Maraschin (2017); Maldaner (2017); Castaman e Nogueira (2018). Evidenciam-se, de maneira geral nas produções, algumas das características das proposições políticas na EPT: fragmentação, morosidade e dualismo de classe (SOUZA et al., 2014). É preciso considerar, tal como nos adverte Maldaner (2017), que "a formação de professores para a EPT não é neutra. Sendo intencional, nas diferentes épocas, mantém um compromisso com um modelo de sociedade, com uma organização societária" (MALDANER, 2017, p. 183); assim, o modelo de EPT, bem como o de formação dos professores para atuação nesta, vão ao encontro de um modelo de sociedade que se pretende.

Analisando o desenvolvimento de proposta de formação docente para os professores da Educação Básica Técnica e Tecnológica (EBTT), Araújo (2014) conclui que a docência aparece, nas políticas educacionais, "como mediação de determinado processo social, que expressa e transmite, nesse caso, a educação como instrumentalização de mão de obra, voltada para a reprodução ampliada do capital" (ARAÚJJO, 2014). Nesse sentido, se o que se pretende é uma sociedade mais justa e comprometida com a superação dos mandos e desmandos do mercado, é preciso "superar o histórico de fragmentação, improviso e insuficiência de formação pedagógica que caracteriza a prática de muitos docentes da educação profissional de hoje" (MACHADO, 2008, p. 15). Além disso, é necessário pensar políticas públicas de estado, e não de governo, para a EP, e assegurar que essa educação seja direito garantido, sobretudo à classe trabalhadora, a fim de se instrumentalizar na luta contra as injustiças e desigualdades sociais. $\mathrm{Na}$ contramão dessa superação, o que se tem a partir da publicação da MP n. 746 de setembro de 2016 (BRASIL, 2016), que prevê que profissionais com notório saber sobre as áreas técnicas possam ministrar aulas nos cursos 
técnicos e profissionais, sem formação pedagógica para tal, é o reforço da segregação - educação para a classe trabalhadora $X$ educação para elite, assim é que "os itinerários formativos escondem uma antiga segregação da educação profissional e da educação básica, reafirmando a educação oferecida à classe trabalhadora" (SILVEIRA; GONÇALVES; MARASCHIN, 2017, p. 810).

Machado (2011) apresenta alguns dados sobre a formação docente para a EPT no Brasil, apontando, em suas análises, alguns desafios a serem enfrentados: na EPTNM, menos de $60 \%$ dos professores possuem licenciatura; menos de $12 \%$ não contam com curso superior concluído, índice aproximado também para aqueles com apenas ensino médio. Entre os desafios a serem enfrentados em prol de uma EPT de qualidade, a autora destaca a necessidade de: garantir não só a sustentabilidade pedagógica, como também de gestão, expansão, interiorização e democratização dos cursos técnicos e daqueles de formação inicial e continuada; revogarem-se os instrumentos legais que têm mantido um caráter precário da profissão docente; regulamentar a oferta de licenciaturas para a EPT, sendo sua oferta ampliada; expandir e aprofundar a política de formação continuada para o Programa Nacional de Integração da Educação Profissional com a Educação Básica, na modalidade da Educação de Jovens e Adultos (PROEJA); incentivar a produção de pesquisas incluindo a participação dos professores; e, por fim, promover o fortalecimento da identidade profissional docente.

Considerando o contexto dos Programas Especiais de Formação Pedagógica, Vieira et al. (2014) destacam que, embora os professores não licenciados, em seu período inicial de formação, não tenham cogitado a docência como profissão, quer pelo desprestígio profissional quer pela representação social da docência, o ingresso no Programa, além de uma exigência legal e pedagógica, ampliou suas oportunidades, melhorou a renda familiar e também a prática pedagógica com a aquisição de saberes próprios da docência, mudando suas concepções. Os autores expõem que, entre as mudanças de concepções, estão aquelas que se referem à sensibilidade às diferenças entre as pessoas, à organização do trabalho em sala de aula, à compreensão do papel do professor na EP, à melhora na prática de ensino com reflexão sobre novas formas de ensinar. Castaman e Nogueira (2018) identificaram, em pesquisa realizada com alunos/professores formados em outras áreas e que participaram do curso de formação pedagógica, via Programa Institucional de Bolsas de Iniciação Docência (PIBID), as contribuições para a formação docente na EPT. Segundo as autoras, a participação no PIBID favoreceu, a alunos e professores, a compreensão dos alunos do espaço escolar e do que é ser um professor pesquisador que reflete sobre a sua prática, buscando relações entre a teoria e a prática no desenvolver do curso.

\section{O CONTEÚDO DA FORMAÇÃO INICIAL E CONTINUADA}

Menos frequentes nos trabalhos levantados, mas não menos relevantes, são aqueles temas que tratam da formação continuada dos 
professores, bem como do conteúdo a ser ofertado nas formações inicial e continuada. Sobre a formação continuada, destacam-se os artigos de Paiva, Correia e Batista (2017); Cavalcante e Henrique (2018); e Pena (2018b). Professores em momentos distintos de sua carreira apresentam demandas diferentes em sua formação continuada. Particularmente na EPT, os professores têm ponto de partida e de formação, muito diferentes uns dos outros. Há licenciados que desconhecem a realidade da EP e, para estes, Paiva, Correia e Batista (2017) destacam a necessidade de uma

\begin{abstract}
formação continuada específica que Ihe[s] aproxime à problemática das relações entre trabalho e educação e ao campo da educação profissional, colaborando com a integração entre trabalho, ciência, tecnologia e cultura, visto que os cursos de licenciatura, em geral, não abordam estudos sobre esse campo da educação. (PAIVA; CORREIA; BATISTA, 2017. p. 167)
\end{abstract}

Também, há técnicos, bacharéis e tecnólogos que, apesar do significativo conhecimento em sua área específica, desconhecem os aspectos pedagógicos da docência. Neste sentido, Cavalcante e Henrique (2018) advertem que o professor tem o desafio de superar a sua própria formação, e a pesquisa se apresenta como uma possibilidade de formação continuada: "a formação pela pesquisa permite que o sujeito desenvolva sua autonomia e o espírito interrogativo, o que possibilita aprendizados que superam a mera reprodução de informações na perspectiva de uma possível intervenção na realidade" (CAVALCANTE; HENRIQUE, 2017, p. 17).

Pesquisando sobre as necessidades formativas de docentes iniciantes no IFMG - campus Ouro Preto, Pena (2018b) identificou, a partir das demandas dos docentes, quais seriam suas prioridades quanto à formação continuada, a saber: na categoria Planejamento, as prioridades foram seleção de metodologias de ensino e elaboração de instrumentos avaliativos; na categoria Currículo, têm-se a implementação do currículo integrado e a integração de disciplinas no curso; na categoria Processos de Ensino-aprendizagem, apontaram-se o trabalho com alunos com defasagem de conhecimentos anteriores, relacionamento professor-aluno, inclusão de alunos com necessidades educacionais especiais; por fim, na categoria Aspectos específicos da Educação Profissional e Tecnológica, foram mencionadas verticalização do ensino, formação dos alunos para o mundo do trabalho, organização e normas acadêmicas internas à Instituição, diversidade no perfil dos alunos das diferentes modalidades, cursos/níveis de ensino (PENA, 2018b, p. 12).

Sobre o conteúdo a ser ofertado nas formações inicial e continuada, contribuem para a reflexão os estudos de Moura (2008); Morais e Henrique (2014); Santos e Azevedo (2016); e Nascimento e Azevedo (2017). A fim de superar alguns desafios presentes na EP, Moura (2008) propõe que essa formação ultrapasse a aquisição de técnicas didáticas de transmissão de conteúdos; assuma a preocupação com o ser humano e não exclusivamente com o mercado/fortalecimento da economia; compreenda o professor não como um transmissor, mas como um mediador no processo de 
ensino e aprendizagem, que possui autoridade e responsabilidade, aliado à competência técnica própria da sua área do conhecimento; se oriente de forma crítica e reflexiva, pautando-se na responsabilidade social; e, finalmente, ultrapasse os limites da educação bancária ${ }^{4}$. Para Nascimento e Azevedo (2017), é preciso que se articule a tecnologia, entendida como ciência da técnica, à formação profissional docente. A esse respeito, Santos e Azevedo (2016) acrescentam que os conceitos relacionados à tecnologia e seus fundamentos iniciais devem favorecer uma EP mais humanizada, possibilitando a inserção de novos saberes na prática docente. Particularmente, no caso de professores licenciados que atuam na EP, Morais e Henrique (2014) apontam a necessidade de inclusão da discussão e sistematização de conhecimentos relativos ao mundo do trabalho, da EP e do ensino médio integrado, e da aproximação trabalho, educação e o mundo da EP.

\section{A ATUAÇÃO DOCENTE NA EPT}

Sobre a atuação docente na EPT, temos os estudos de: Negrini e Cruz (2008); Shiroma e Lima Filho (2011); Gomes, Brasileiro e Lima (2014); Pasqualli, Vieira, J., Vieira, M. (2015); Flach (2015); Predebon Titon (2016); Virgem (2016); Kreutz e Welter (2016); Da Silva, Queiroz e Medeiros (2017); Morais, Santos e Brandão (2017); e Motta, Cavalcante e Lemos (2018).

A atuação dos docentes na EPT, particularmente dos professores de disciplinas técnicas/específicas, encontra-se fortemente marcada pela atuação em indústrias, fábricas, hospitais, enfim, em outros espaços não escolares. Nesse sentindo, Negrini e Cruz (2008) traçam aproximações e distanciamentos entre esses espaços (fábrica-escola). Os resultados apontam para a consciência de alguns professores sobre a necessidade de "saber pedagogia" para atuar no espaço escola, reconhecendo que, se a profissão mudou (de empregado na indústria para a de professor), é preciso que as "técnicas" também mudem para atender às demandas da nova profissão. Para Kreutz e Welter (2016), é fundamental que o professor se mantenha inserido no mercado, entendido como trabalho fora da escola, tendo assim dupla carreira; mas reconhecem que essa dupla jornada pode comprometer a motivação do professor, em função da carga horária excessiva. Acrescente-se a isso o fato de que a docência pode correr o risco de ser vista como um bico, um complemento salarial, e não ser reconhecida como profissão principal. Segundo Morais, Santos e Brandão (2017), é recorrente que os professores da EP vejam o trabalho docente como extensão do trabalho anteriormente desenvolvido em outros espaços. Muitos consideram, de maneira acrítica, que a EP tem como função atender às demandas do mercado de trabalho.

O PROEJA se apresenta como outra possibilidade de atuação docente na EPT; no entanto, tal como afirmam Shiroma e Lima Filho (2011),

\footnotetext{
${ }^{4}$ A expressão educação bancária, fortemente criticada por Paulo Freire, parte do pressuposto de que o aluno nada sabe e que o professor é o detentor de todo o saber, o qual será "depositado" neste aluno. 
no interior dos IFs, existe uma hierarquia pela procura dos cursos/níveis e modalidades, por parte dos docentes, sendo que o PROEJA ficaria em um nível menor de interesse e procura. É comum que, para estes cursos, professores temporários e substitutos sejam direcionados (SHIROMA; LIMA FILHO, 2011, p. 736).

A atuação de professores licenciados na EPT, por sua vez, demonstra outras especificidades, que de maneira geral revelam a fragilidade da formação inicial recebida. Da Silva, Queiroz e Medeiros (2018) as destacam: capacitar para o exercício de uma profissão, conhecer a área técnica de formação, dominar saberes didáticos de natureza científico-reflexiva e dominar saberes de pesquisador.

Pena (2018b) identificou, entre os sujeitos que participaram da pesquisa, que $23 \%$ dos docentes atuam no ensino técnico e no ensino superior (cursos de licenciatura e/ou tecnólogos). Entre os que atuam nas licenciaturas, Flach (2015) sinaliza para uma identidade ainda em construção, ora se aproximando da atuação dos professores universitários, ora se aproximando da EPT, em que o campo de atuação e de formação se aproxima do mundo do trabalho. Nesse sentido, Predebon Titon (2016) investigou a formação de professores de Matemática e Física, nos IFs, a fim de verificar se o perfil dos professores formados pelos IFs atenderia ao proposto nos documentos oficiais e às demandas do mercado de trabalho; no entanto, o resumo não apresenta as conclusões do trabalho.

A atuação docente na EPT passa pela mediação tecnológica, como forma de favorecimento do processo de ensino e aprendizagem, tal como aponta a pesquisa de Virgem (2016). Soma-se à docência na EPT, a possibilidade de atuar em projetos de extensão. Tais projetos, quando ocorrem nas licenciaturas ofertadas pelos IFs, permitem aos estudantes a inserção na realidade das escolas. Desta forma, segundo Motta, Cavalcante e Lemos (2018), o trabalho colaborativo permite a articulação de conhecimentos teóricos e metodológicos na formação profissional docente. Por fim, Pasqualli, Vieira, J., Vieira, M. (2015) apresentam a atuação dos professores da EPT a distância; a estes, falta formação para a docência, mas, também, formação para a educação a distância e domínio das tecnologias. Nesse contexto, a prática se torna o principal local de formação.

\section{CONSIDERAÇÕES FINAIS}

Pela análise que se fez da produção científica dos últimos dez anos sobre a formação e a atuação dos docentes da EPT, percebe-se que há um interesse maior dos pesquisadores em discutir a formação desses professores. No entanto, os resultados das pesquisas pouco têm sido contemplados na elaboração de políticas educacionais voltadas para a formação desses professores. Essas políticas, por vezes, representam um retrocesso, tal como revela a MP n. 746/16, em que a formação docente não é nem sequer necessária. 
Uma alternativa para que a formação docente na EPT se efetive passa necessariamente pelo espaço de atuação do docente. Os IFs, de maneira particular, guardam a potencialidade de fomentar essa formação, dada a qualificação de seu quadro docente e as condições de trabalho com que contam. Iniciativas como programas de desenvolvimento profissional docente são capazes de, partindo das necessidades formativas reais e locais, propor formações que contemplem diferentes aspectos da prática pedagógica na EPT.

Pelo número reduzido de trabalhos encontrados, importa-nos registrar a necessidade de que os pesquisadores voltem os seus olhos para o espaço, os sujeitos e as ações da/na EPT, ampliando os estudos nos IFs; mas, também, na rede privada, principal agente na oferta de EPT no país.

\section{REFERÊNCIAS}

\section{ARAÚJO, W. P. A formação docente para a Educação Profissional e Tecnológica no}

IFNMG - campus Januária. 2014. 195 f. Dissertação (Mestrado em Educação) - Universidade de Brasília, Brasília, 2014.

BRASIL. Conselho Nacional de Educação. Resolução no 2 de 26 de junho de 1997. Dispõe sobre os programas especiais de formação pedagógica de docentes para as disciplinas do currículo do ensino fundamental, do ensino médio e da educação profissional em nível médio. Brasil, Brasília, DF, 26 de junho de 1997.

BRASIL. Presidência da República. Lei no 11.892, de 29 de dezembro de 2008. Institui a Rede Federal de Educação Profissional, Científica e Tecnológica, cria os Institutos Federais de Educação, Ciência e Tecnologia, e dá outras providências. Brasil, Brasília, DF, 29 de dezembro de 2008.

BRASIL. Presidência da República. Medida Provisória, no 746, de 22 de setembro de 2016. Institui a Política de Fomento à Implementação de Escolas de Ensino Médio em Tempo Integral. Brasil, Brasília, DF, 22 de setembro de 2016.

CASTAMAN, A. S.; NOGUEIRA, C. G. Contribuições do Programa Institucional de Bolsas de Iniciação à Docência (PIBID) para a formação docente na Educação Profissional. Revista Brasileira da Educação Profissional e Tecnológica. v. 2, n. 15, 2018.

CAVALCANTE, I. F.; HENRIQUE, A. L. S. A experiência da pesquisa na formação docente: unindo teoria à prática. Revista Brasileira da Educação Profissional e Tecnológica. v. ,1. n. 12, 2018.

COSTA, A. M. F. da.; FONSECA, C. M. F.; COSTA, L. de G. M. Desvelando o percurso formativo de docentes da Educação Profissional: um estudo de caso com professores do curso de análises clínicas em uma IES privada. Revista Brasileira da Educação Profissional e Tecnológica. v. 1, n. 12, 2017. 
DA SILVA, K. K. O.; QUEIROZ, K. da S.; MEDEIROS, S. M. D. Trabalho e trabalho docente: a percepção de docentes da área de formação geral. Revista Brasileira da Educação Profissional e Tecnológica. v. 1, n. 12, 2017.

FLACH, A. Formação de Professores nos Institutos Federais: uma identidade por construir. In: REUNIÃO ANUAL DA ANPED, 37, 2015, Florianópolis, Anais... GT8: Formação de Professores, Florianópolis, 2015.

FONSECA, C. M. F. da. Formação e saberes docentes na Educação Profissional: um relato de experiência. Revista Brasileira da Educação Profissional e Tecnológica. v. 1, n. 12, 2017.

GOMES, S. S. W.; BRASILEIRO, R. M. O.; LIMA, P. R. Identidade profissional e trabalho docente: o que dizem os professores dos cursos de licenciatura do IFAL. Revista Brasileira da Educação Profissional e Tecnológica. v. 1, n. 7, 2014.

KREUTZ, D. H.; WELTER, C. B. Professor em (re) construção: reflexões de um docente em formação pedagógica. Revista Brasileira da Educação Profissional e Tecnológica. v. 2, n. 11, 2016.

MACHADO, L. R. de S. Diferenciais inovadores na formação de professores para a Educação Profissional. In: Revista Brasileira da Educação Profissional e Tecnológica. v. 1, n. 1, 2008.

MACHADO, L. R. de $S$. $O$ desafio da formação dos professores para a EPT e PROEJA. Educação e Sociedade, Campinas, v. 32, p. 689-704, jul/set, 2011.

MALDANER, J. J. A formação docente para a Educação Profissional e Tecnológica: breve caracterização do debate. Revista Brasileira da Educação Profissional e Tecnológica. v. 2, n. 13, 2017.

MORAIS, J. K. C.; HENRIQUE, A. L. S. O professor licenciado na Educação Profissional: quais saberes docentes alicerçam seu trabalho? Revista Brasileira da Educação Profissional e Tecnológica. v. 1, n. 7, 2014.

MORAIS, J. K. C. SANTOS, M. G. M. BRANDÃO, P. A. F. O caminho dos professores na Educação Profissional: percepções sobre o sentido do trabalho e do trabalho docente. Revista Brasileira da Educação Profissional e Tecnológica. v. 1, n. 12, 2017.

MOTTA, T. C.; CAVALCANTE, I. F.; LEMOS, E. Política de extensão na perspectiva colaborativa pela formação docente. Revista Brasileira da Educação Profissional e Tecnológica. v. 1, n. 14, 2018.

MOURA, D. H. Formação de docentes para a Educação Profissional e Tecnológica. In: Revista Brasileira da Educação Profissional e Tecnológica. v. 1, n. 1, 2008.

NASCIMENTO, E. D'A.; AZEVEDO, R. O. M. Possíveis articulações entre os conceitos de tecnologia e competências na formação profissional docente. Revista Brasileira da Educação Profissional e Tecnológica. v. 2, n. 13., 2017. 
NEGRINI, E. A.; CRUZ, M. N. da. Aproximações e distanciamentos entre o trabalho na indústria e na escola: uma análise dos sentidos da docência produzidos por professores de Educação Profissional. In: REUNIÃO ANUAL DA ANPED, 31, 2008, Caxambu. Anais... GT8: Formação de Professores, Caxambu, 2008.

OLIVEIRA, M. R. N. S. Formação e profissionalização dos professores do ensino técnico. In: ARANHA, A. V. S.; CUNHA, D. M.; LAUDARES, J. B. (Orgs.). Diálogos sobre trabalho: perspectivas multidisciplinares. Campinas, SP: Papirus, 2005.

PAIVA, S. Y. de.; CORREIA, D. S. de B.; BATISTA, A.C. 0 perfil de formação de professores da educação profissional que atuam em instituições privadas no RN: uma análise a partir das vozes dos docentes do eixo geral. Revista Brasileira da Educação Profissional e Tecnológica. v. 1, n. 12, 2017.

PASQUALLI, R.; VIEIRA, J. A.; VIEIRA, M. M. M. Formação de professora para a Educação Profissional e Tecnológica a distância da Rede Federal de educação brasileira: análises das produções acadêmicas. Revista Brasileira da Educação Profissional e Tecnológica. v. 2, n. 9, 2015.

PENA, G. A. de C. Docência na educação profissional e tecnológica: conhecimentos, práticas e desafios de professores de cursos técnicos na rede federal. 2014, 290 f. Tese (Doutorado em Educação) - UFMG, Belo Horizonte, MG, 2014.

PENA. G. A.de C. Perfil dos docentes dos Institutos Federais: estudo de caso no IFMG. Relatório final. IFMG, Ouro Preto, 2018a.

PENA. G. A. de C. Necessidades formativas de professores dos Institutos Federais e desenvolvimento profissional docente. Revista Brasileira da Educação Profissional e Tecnológica. v. 2, n. 15, $2018 \mathrm{~b}$.

PIRES, F. T. 0 saber docente que orienta a atuação didática de professores que ministram as disciplinas técnicas na Educação Profissional Técnica de Nível Médio. 2015. 206 f. Dissertação (Mestrado em Educação Tecnológica). Programa de Pós-graduação em Educação Tecnológica, Centro Federal de Educação Tecnológica de Minas Gerais, Belo Horizonte, MG, 2015.

PREDEBON TITON, F. Formação inicial e perfil profissional docente: um estudo de caso no âmbito dos Institutos federais de Educação, Ciência e Tecnologia. 2016, 348 f. Tese (Doutorado em Educação em Ciências: Química da Vida e Saúde). Universidade Federal do Rio Grande do Sul, Porto Alegre, 2016.

RODRIGUES, M. R. S. L.; FREITAS, M. C. S. Formar-se para ensinar: experiência de um Instituto Federal. Revista Brasileira da Educação Profissional e Tecnológica. v. 2, n. 11, 2016.

ROSA, A. P.Q. Itinerâncias Rizoéticas: saberes e formação docente na Educação Profissional e Tecnológica (EPT). 2012, 318 f. Tese (Doutorado em Educação). Universidade Federal da Bahia, Salvador, 2012. 
SANTOS, A. P. D.; AZEVEDO, R. O. M. Saberes docentes na Educação Profissional Técnica de Nível Médio: uma proposta para a formação de professores do IFAM - campus LÁBREA. Revista Brasileira da Educação Profissional e Tecnológica. v. 2, n. 11, 2016.

SHIROMA, E. O.; LIMA FILHO, D. L. O trabalho docente na Educação Profissional e Tecnológica e no PROEJA. Educação \& Sociedade, Campinas, v. 32, n. 116, p. 725-743, jul/set, 2011.

SILVA, C. J. R. (Org.). Institutos Federais lei 11.892. de 29/11/2008: comentários e reflexões. Natal: IFRN, 2009.

SILVA JÚNIOR, G.S.; GARIGLIO, J. A. Saberes da docência de professores da Educação Profissional. Revista Brasileira de Educação. v. 19, n. 59, out-dez, 2014.

SILVEIRA, R. B.; GONÇALVES, L. F.; MARASCHIN, M. S. A formação de professores na Educação Profissional e Tecnológica, e a complexidade que envolve a permanência e êxito dos estudantes. Revista Brasileira da Educação Profissional e Tecnológica. v. 2, n. 13, 2017.

SOUZA, A. C. R.; ANDRADE, M. C. F.; AGUIAR, A. F. S A formação de professores para o ensino profissional no Brasil: a construção de um caminho. Revista Brasileira da Educação Profissional e Tecnológica. v. 1, n. 7, 2014.

SOUZA, A. C. R.; VILAS BOAS, M.; VILAS BOAS, T.; AGUIAR, A. Saberes pedagógicos e história das Ciências no processo formativo de professores da Educação Profissional. Revista Brasileira da Educação Profissional e Tecnológica. v. 1, n. 7, 2014.

VIEIRA, M. M. M.; VIEIRA, J. A.; PASQUALLI, R. Formação de Professores da Educação profissional nos Programas Especiais de Formação Pedagógica. Revista Brasileira da Educação Profissional e Tecnológica. v. 1, n. 7, 2014.

VIRGEM, L. A. M. Aprendinsi: metodologia híbrida de ensino e aprendizagem baseada em problemas/projetos e escuta ativa para formação docente em educação profissional e tecnológica. 2016. $152 \mathrm{f}$. Dissertação (Mestrado Interdisciplinar e Profissional em Desenvolvimento e Gestão Social). Universidade Federal da Bahia, Salvador, 2016. 